\title{
Mas, afinal, o que é Educação Física?: \\ um exemplo do simplismo intelectual
}

Celi Nelza Zulke Taffarel

Micheli Ortega Escobar

\section{RESUMO}

O trabalho expõe uma crítica às concepções idealistas que se constituem em referências para o autor do artigo "Mas afinal, o que é Educação Física?" e procura responder aos problemas, de ordem filosófica, epistemológica, metodológica e política, levantados pela pergunta. As contribuições das autoras surgem da radicalização da crítica a partir dó marco teórico e metodológico materialistahistórico-dialético.

Recife, 30 de Novembro de ! 993.

\section{"MAS AFINAL, O QUE É EDUCAÇÃO FÍSICA?: UM EXEMPLO DO SIMPLISMO INTELECTUAL"}

Em texto recente, apresentado pelo professor Adroaldo Gaya, em aula inaugural ministrada na ESEF/ UFRGS, intitulado "Mas afinal, o que é Educação Física?", o autor nos acena com a volta ao simples, como caminho para encontrar respostas ao que, afinal, seja Educação Física.
Por solicitação do editor da revista Movimenta estamos apresentando este primeiro texto de uma série, com o objetivo de instigar reflexões mais profundas sobre o tema, onde explicitaremos elementos para contestar uma definição de Educação Física elaborada idealisticamente. (Lenine, 1982).

Não é nova, no seio da intelectualidade, a utilização de recursos desmobilizadores da reflexão e do debate político e ideológico, como os de "colocar como referência a própria ausência de referências", ou de "voltar ao simples" (Freitas, 1991), assim desconhecendo, ingenuamente e sem sutilezas, as relações sociais subjacentes à produção do conhecimento $\mathrm{e}$ à prática pedagógica.

A definição de Educação Física, apresentada por Gaya em sua aula inaugural ESEF/UFRGS, setembro/ 1993, tem como ponto de partida a recorrência cultural ${ }^{(1)}$ ao simplismo - próprio das tendências onde prevalece a incerteza, a volta ao passado, a busca de raízes étnicas - para sistematização do conhecimento, produzido sobre o assunto. Essa recorrência pode ser exemplificada e reconhecida no seu texto quando apresenta a produção do conhecimento a partir de referências regionais como: França - Le Boulch, J., Parlebas, P.; Espanha Cadigal, J.M., Pedraz, M. V., Moreno, J.H., Lopez, J. R.; países de língua inglesa Brooks, G.A.,-Henry, MF.M., Rarick,G.L, Park, R. J., Newell, K. M., Renson, R., Higgins, J.R., Brooke, J. D., Whitting, H. T. A, Katch, F. I., Sabbo, D. G. H., Glas-seford, R. G.; Alemanha Haag, H., Grupe, O., Kirch, A., Willimczik, K., Meinberg, E.; na ex RDA- Bauersfeld, K. H., Adam, Y.; Dinamarca Eichberg, H.; Portugal - Sérgio, M., Sobral, F., Proença, J., Bento, O., Constantino, J. M., Marques, A.; Brasil - Oliveira, V. M., Medina, J..P. S., Da Costa, L. P., Santin, S., Faria Júnior, A., Teixeira, LA, Tani, G., Canfield, J. T., Do Carmo, A. A, Bracht, V., Lovisolo, H., Farinatti, P. T. V. (2)

Na sua análise, Gaya 
encontra duas tendências nos estudos. A primeira, predominante, considera a Educação Física como uma ciência relativamente autônoma e uma disciplina acadêmica e/ou científica que alimenta duas perspectivas: uma que pretende colocar, em um ú n i co e s p a ço de investigação, as diferentes formas de expressão da cultura corporal, tais como a ciência da motricidade humana, ciência do movimento, ciências do exercício, cinesiologia ou cineantropologia, a psicocinética ou a praxiologia e outra que pretende a criação de um espaço capaz de abarcar toda e qualquer disciplina científica que, de alguma forma, trate de questões referentes ao desporto como prática corporal e motora específica, tal como as ciências do desporto e ciências do treino desportivo.

A segunda tendência, cética quanto a hegemonia do conhecimento científico que entende a Educação Física como filosofia da corporeidade e, também, a present a d u a s perspectivas: a primeira , existencialista, configura a Educação Física no discurso filosófico da corporeidade, dando ênfase ao lúdico, à sexualidade, às práticas alternativas de expressão corporal; e a segunda, culturalista, que prevê a reconstrução da Educação Física na ótica do lazer, dos jogos populares e tradicionais.

A posição do autor, expressa na citação "(...) É necessário voltar às coisas simples, à capacidade de formular perguntas simples (...)" (Santos, 1991, p.6), o conduz a esta análise simplista e reducionista do fenômeno. Os autores mencionados a princípio; não mereceram sua crítica rigorosa, nem do ponto de vista da hermêutica de Ricoueur.

A limitação da possibilidade crítica de Gaya, ao analisar estas tendências, pode ser explicada pela ausência da categoria "atividade", no sentido marxista, explicativa das mudanças trazidas pelo modo de produção capitalista - por exemplo, e entre outros - à atividade lúdica do homem, que deve ser entendida como toda atividade humana, a qual

"aparece como um sistema incluído no sistema de relações da sociedade. A $a \quad t \quad i \quad i \quad d \quad a$ -

"A definição de Educação Física, apresentada por Gaya, tem conto ponto de partida a recorrência cultural ao simplismo para sistematização do conhecimento produzido sobre o assunto ". de humana não existe em absoluto fora destas relações. (...) Quando se analisa a atividade temos que assinalar que a atividade objetiva gera não somente o caráter objetivo das imagens, senão também a objetividade das necessidades, das emoções e dos sentimentos". (Leontiev, 1979, p.l1-14).

$T$ o d a v i a , argumentações como as de Gaya e dos autores que ele analisa de forma simplista, explicam-se pela não consideração da Educação Física como produção não material que, em determinados estágios e pela influência de certos fatores próprios do sistema capitalista, sofre o mesmo processo de privação das suas qualidades sensíveis sofrido pela produção material.

"(...) o absurdo social de que o processo vivo da a propriação da natureza pelo homem e das relações sociais por ela medidas assumem a forma de propriedades de objetos mortos. A atividade viva dos homens é absorvida, por assim dizer, por seus próprios produtos, que por esse mecanismo absurdo são promovidas a quase-sujeitos da sociedade, enquanto os homens, seus criadores, são degradados a meros acessórios)...)"-(Kurz, 1992, p.240). 
G a y e sua s referências não levam em conta a relação do desenvolvimento geral da sociedade e da sua base material como determinante da "qualidade" da produção da cultura corporal, que, em um modo de produção capitalista, sobrepõe ao caráter lúdico das atividades a v i o l ê n c i a, a competitividade exacerbada, a estimulação por drogas, enfim, os subprodutos da cultura dos "esportes de altos rendimentos".

Admitimos que as perguntas podem ser simples, mas, para respondê-las, precisamos de pensamentos complexos; nisto filósofos europeus concordam, a exemplo de Edgar Morin (1986), defensor da necessidade da mudança do modo de pensar.

À pergunta: "O que é Educação Física? Será ciência, ou será filosofia?" o a u tor, e m s e u pronunciamento durante a aula inaugural, responde coma definição, "(...) a Educação Física é uma disciplina normativa" (1993:7), alegando que "(...) as demais tendências que inferem a possibilidade de reduzir a Educação Física exclusivamente a uma ciência, ou a uma filosofia, acabam por destruí-la de seu real significado social e, mais do que isto, apontam para a descaracterização de nossa identidade profissional". Argumenta que á Educação Física é consubstanciada numa pedagogia com objetivos formativos, não podendo resumir-se apreensão do real a partir de representações, a exemplo da forma como o esporte é considerado na escola, abordado como uma atividade abstrata - como um trabalho cujo dispêndio de força vai além das necessidades concretas - e sem avaliar a qualidade destrutiva da socialização subjacente a essa concepção*.

Não ficam por aqui os equívocos teóricos. $\mathrm{O}$ autor menciona que a prática da Educação Física efetua-se segundo princípios advindos do conhecimento científico, e que estes fundamentos determinam sua práxis. Desconsidera que as determinações da prática social da Educação Física, em última instância, não advêm de "fundamentos" pré-concebidos, mas de possibilidades, históricas para ela colocadas. Desconsidera, ainda, que o movimento do pensamento para apreender esta prática social pode-se dar em bases pré-conceituais, pré-científic a s, a t r a vé s d e representações, ou com bases conceituais que revelam a essência, as leis internas do fenômeno.

É este "movimento do pensamento", demonstrado pelos raciocínios de Gaya que aponta para a necessidade de uma nova racionalidade (Edgar Morin 1986, Gorz 1993). O idealismo é insuficiente para apreender os fenômenos sociais concretos.

$\mathrm{Na} s$ a a dos equívocos teóricos o autor admite 
que"(...) nesse quadro onde convergem conteúdos diversos (da biologia, antropologia, sociologia, psicologia, etc.) configura-se um espaço multidisciplinar onde se percebe uma profunda ausência de objetivos e objetos comuns, ficando, desta forma, destituídas de uma definição e p istemológ i c a e metodológica capaz de responder às necessidades inerentes aos intervenientes da Educação Física". Com esta afirmação, o autor comete dois enganos. De um lado, reporta esses interesses ao plano abstrato das disciplinas, ignorando completamente os interesses humanos e de classe na prática social de Educação Física e, do outro I a d o, a bord a a multidisciplinaridade a partir de "objetivos comuns", desconsiderando o processo de trabalho concreto onde ocorre a produção de conhecimento, o qual é historicamente determinado e configura interesses de classes antagônicas presentes no modo de produção e de reprodução da vida capitalista.

Gaya demonstra desconhecer, ou relega por escolha pessoal, a teoria dialética materialista histórica de produção e apropriação social do conhecimento, por isto admite que "enquanto no âmbito do conhecimento científico se discute as definições de seus objetos teóricos, ou seja, enquanto os discursos científicos procuram responder aos critérios inerentes aos juízos epistemológicos, a prática da Educação Física enfrenta o desafio que, entretanto, se coloca ao homem concreto".

Sustenta a Educação Física como projeto pedagógico, afirma que á "Educação" e parte do conceito de Educação geral, como sendo o "(..) desenvolvimento da p e r son a l i d a d e, desenvolvimento das capacidades físicas, motoras, intelectuais, afetivas e morais dos seres humanos, visando sua atuação na sociedade". Fica aqui evidente uma concepção de Educação completamente superada, porque idealizada, fora do contexto da escola capitalista em cujo interior confrontam-se interesses hegemônicos e emergentes que a colocam em tensão entre dois pólos: propiciar a emancipação humana ou favorecer a alienação, determinados pelos movimentos

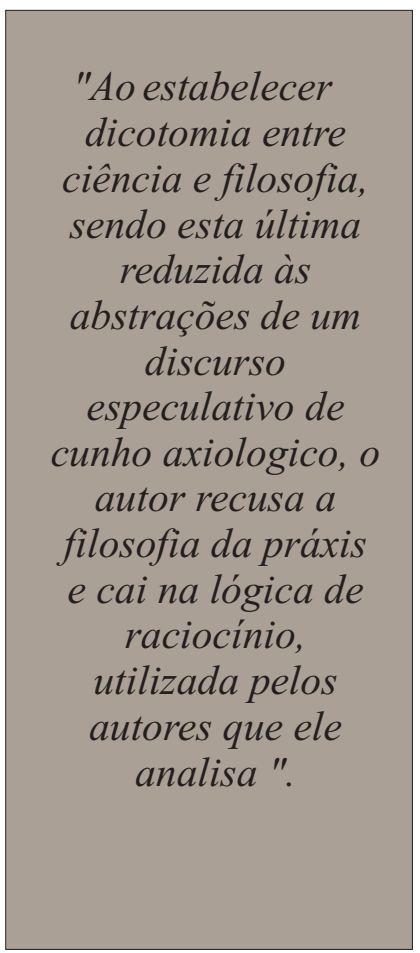

sociais organizados e pela realidade conjuntural. (Duarte, 1 992). Isto é negado, demonstrando, mais uma vez, seu raciocínio idealista.

O exame crítico do pensamento de Gaya nos põe de relevo sua concepção de filosofia e de ciência, baseadas em representações do real. Ao estabelecer dicotomia entre ciência e filosofia, sendo esta última reduzida às abstrações de um discurso especulativo de cunho axiológico, o autor recusa a filosofia da práxis e cai na lógica de raciocínio, utilizada pelos autores que ele analisa. Estabelece cisões e fragmentações que expressam, no seu p e n s a m e to, a s fragmentações instaladas na produção do conhecimento no modo capitalista. Afirma que o que faz interagir a ciência e a filosofia é a Educação Física "na ação de ensinar, na ação de conduzir", concluindo, equivocadamente, que a ação pedagógica seria capaz de concretizar a interação axiologia $x$ epistomologia. Aposição de Gaya nos parece ser a de

"(...)Um abstrato
sujeito cognoscente,
de um a m ente
pens a nte, que
examina a realidade
especulativamente"
(Kosik, 1976, p. 9-33).
A radicalização da
preensão dialética
erialista histórica,
uanto teoria do
hecimento, nos
sibilita apontar o
ívoco das deno-
naçõ e s t ter-


minologias - empregadas pelos autores citados por Gaya e que buscam delimitar objetos de estudo para a Educação Física tais como "movimento humano, psico-cinética, ciências do esporte; ciências do desporto e motricidade humana", colocados no marco referencial das concepções idealistas e da referência cientifica empírico-analítica, hermêutica e fenomenológica. Nelas fica evidente um recorrer às ciências humanas e sociais somente para legitimar uma perspectiva filosóficocientífica superada, esgotada, que é o idealismo e o método empíricoanalítico de pesquisa.

Gaya deixa evidente neste texto, não admitir que - fazer científico se dá dentro de determinadas relações históricas que caracterizam a ciência enquanto: a) força produtiva - pois quando incorporada aos processos produtivos aumenta a produtividade, 0 rendimento, a mais-valia, assegurando a acumulação do capital e as condições que o perpetuam; b) dominação política - pois quando incorporada à sociedade industrial, à modernidade e à pósmodernidade, por uma política de racionalidade científico-tecnológica assumida pelo Estado, determina condições de vida, processos de trabalho, de acesso a bens culturais como educação, saúde, segurança; c) ideologia pela sua subjunção aos interesses das classes dominantes, mediatizados pelo Estado e expressos

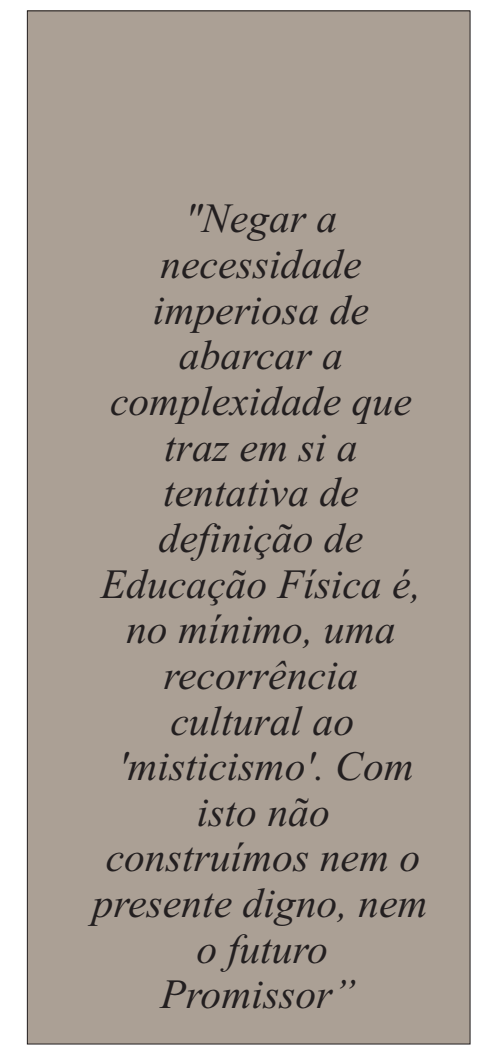

em leis, planos e diretrizes governamentais e administrativas (Sobral, 1988).

Nas reflexões de Gaya sobre o que é Educação Física estas dimensões da ciência são ignoradas. Repete, assim, em sua análise, os enganos do que se propõe a analisar.

Completa o quadro de equívocos - de teses falsas porque sustentadas em pseudo-conceitos e era formas fenomênicas - a Educação Física entendida como uma Pedagogia, no âmbito de um projeto antropológico. Afirma o autor: "Devemos ter claro que a Educação Física é uma intervenção no real concreto a partir de objetivos práticos". Absurdo teórico. Já manifestamos que a intervenção no real está na dependência da qualidade da práxis social, historicamente deter-
Minada no marco de produção da vida e segundo interesses de classe. Negar a necessidade imperiosa de abarcar a complexidade que traz em si a tentativa de definição de Educação Física é, no mínimo, uma recorrência cultural ao "misticismo". Com isto não construímos nem o presente digno, nem o futuro promissor.

Nossa expectativa é a de que os brasileiros que estejam estudando na Europa, e Estados Unidos reconheçam as "sucatas científicas idealistas" que Ihes são oferecidas. Nosso receio é que estas "sucatas" q u e brem o brio revolucionário desses homens de valor.

Não vamos cometer o equívoco histórico de, mais uma vez, "trocarmos nosso ouro por espelhos".

\section{REFERÊNCIAS}

BIBLIOGRÁFICAS

ARROYO, Miguel G. Revendo os vínculos entre trabalho e educação: elementos materiais da formação humana. In: SILVA, Tomaz T. Trabalho, Educação e Prática Social. Porto Alegre. Artes Médicas. 199 i.

DUARTE, Newton. A formação do indivíduo e a objetivação do gênero hum a no. Campinas. UNICAMP. Tese Doutorado.Faculdade de Educação, 1992.

FREITAS, Luiz Carlos. Seis teses d o bre a e d u c a ção e a Contemporaneidade. In: VI Encontro de Didática e Prática de Ensino (ENDIPE). Porto Alegre; 199!.Mimeografado.

GAYA, Adroaldo C. Mas afinal, o que é educação Física? Porto Alegre, ESEF/UFRGS, 1993. Mimeografado. 
GORZ, André, A nova Agenda. In: BLACKBURN, Robin (Org.) Depois da queda. $O$ fracasso do comunismo e o futuro do socialismo. $2^{a}$ ed. Rio de Janeiro. Paz e Terra, 1991, p.235 270.

KOSIK, Karel. Dialética do concreto. 2 ed. Rio de Janeiro, Paz e Terra, 1976.

KURZ, R. O colapso da modernização. Da derrocada do socialismo de caserna à crise da economia mundial. 2 ed. Rio de Janeiro, Paz e Terra; 1992.

LENINE, V. Materialismo e Empirocriticismo: Notas críticas sobre uma filosofia reacionária. Lisboa, Progresso, 1982

LEONTIEV, Alexei N. Activvidad, Conciencia, Personalidad. La Habana, Editorial Pueblo y Educación, 1981.

MORIN, E. Para sair do século XX.

Rio de Janeiro, Nova Fronteira, 1986.

SOBRAL, F. A. da F. A produção e a apropriação social da pesquisa científica e tecnológica: uma discussão no capitalismo dependente. Revista brasileira de Estudos Pedagógicos, 67 (156): 287-305, Maio/Agosto, .1986.

RICOUEUR, P. Interpretação e Ideologias. 3 ed. Rio de Janeiro, Francisco Aves, 1988

\section{NOTAS}

1. ecorrência cultural é abordada como sendo o encaminhamento de demandas historicamente forjadas e que buscam ser atendidas, tanto por sujeitos coletivos, de acordo com suas possibilidades de acesso a determinados bens historicamente produzidos. Assim como para os indivíduos que vivem em países industrialmente desenvolvidos, a informática possibilita lidar com a "realidade virtual", os indivíduos que vivem onde prevalecem formas econômicas pré-capitalistas recorrem ao misticismo e ao "miticismo" para lidar com dados da realidade. O que .os aproxima é que a lógica de raciocinar sobre a realidade é baseada em pseudopreconceitos, ou seja representações da realidade. A lógica que os rege.é a da alienação, alienação esta drasticamente acentuada no capitalismo avançado. Ver a respeito deste fenômeno humano, social, psicológico e político a obra. BOTTOMORO, T, Ed.Dicionário do pensamento Marxista. Rio de Janeiro, Zahar, 1983

Estes são os autores analisados por Gaya e referenciados no seu texto.

\section{UNITERMOS}

Educação física, filosofia, ciências, idealismo, materialismo históricodidático.

\section{CELINELZAZULKE TAFFAREL.}

Professora Adjunta do Departamento de Educação Física do Centro de Ciências da Saúde da Universidade Federal de Pernambuco. Doutora em Educação, UNICAMP.

\section{MJCHELI ORTEGA ESCOBAR.}

Professora Adjunta do Departamento de Educação Física do Centro de Ciências da Saúde da Universidade Federal de Pernambuco. Mestranda em Educação, UNICAMP. 